legal restrictions, productivity, energy efficiency, thermoelectric generator, cooling, modelling, MATLAB/Simulink

\author{
Eckart UHLMANN ${ }^{1,2}$ \\ Sebastian SALEIN ${ }^{1 *}$ \\ Mitchel POLTE ${ }^{1,2}$ \\ Florian TRIEBEL ${ }^{1}$
}

\title{
MODELLING OF A THERMOELECTRIC SELF-COOLING SYSTEM BASED ON THERMAL RESISTANCE NETWORKS FOR LINEAR DIRECT DRIVES IN MACHINE TOOLS
}

\begin{abstract}
The use of direct drives in linear and rotary axes as well as increased power density of main drives offer the potential to raise feet rate, acceleration and thus allow higher productivity of machine tools. The induced heat flow rates of these drives could lead to thermo-elastic deformations of precision related machine tool components. In order to reduce thermally caused displacements of the tool-center-point and to prevent a negative impact on the achievable accuracy, the induced heat flow rates of main drives must be dissipated by effective cooling systems. These systems account for a major share of the machine tool's total energy consumption. With the intention to overcome the area of conflict regarding productivity and energy efficiency, a so called thermoelectric self-cooling system has been developed. To convert a proportion of thermal losses into electrical energy, thermoelectric generators are placed in the heat flow between the primary part of a linear direct drive and the cooling system. The harvested energy is directly supplied to a pump of the water cooling circuit, which operates a decentralised cooling system with reasonable coolant flow rates. For predicting the thermoelectric system behaviour and to enable a model-based design of thermoelectric self-cooling systems, a thermal resistance network as a system simulation in MATLAB/Simulink is presented. The model is applied to a feed unit with a linear direct drive and allows the calculation of harvested energy as well as the simulation of steady and transient states of the cooling system. The comparison of simulative and experimental determined data indicates a predominantly high model prediction accuracy with short simulation times. At an early stage of development the model turns out to be a powerful tool for design and analysis of water flow thermoelectric self-cooling systems.
\end{abstract}

\section{INTRODUCTION}

With the aim of higher profitability and the commitment to legal restrictions regarding eco-design measures as defined by directive 2009/125/EC, machine tools are subjected to contrary requirements regarding productivity and energy efficiency $[1,2]$. Following the simplified assumption that expresses productivity by the metal removal rate $Q_{W}$ and energy

\footnotetext{
${ }^{1}$ Institute for Machine Tools and Factory Management (IWF), TU Berlin, Germany

${ }^{2}$ Fraunhofer Institute for Production Systems and Design Technology IPK in Berlin, Germany

*E-mail: salein@iwf.tu-berlin.de https://doi.org/10.36897/jme/117783
} 
consumption by the cutting power $P_{C}$, energy consumption grows proportionally with productivity [3]. In this area of conflict, a common approach to increase productivity is the use of direct drives in linear and rotary axes as well as the rise of power density $\phi$ of main drives. Linear direct drives (LDD) are increasingly applied to allow higher acceleration $a$, feed rate $v_{\mathrm{f}}$ and thus rapid positioning in comparison to conventional ball screw drives $[4,5]$. However, this is accompanied with higher thermal losses at the same generated mechanical power $P_{\text {mech }}$ as one disadvantage of LDD. The electrical power losses of LDD, in form of heat flow rates $\dot{Q}_{\text {ind }}$ are induced into the adjacent machine tool components. Without the use of countermeasures, a temporally and locally changing temperature distribution results. This could lead to thermo-elastic deformations $\Delta l$ of precision related machine tool components, which directly influence the position of the Tool Center Point (TCP), and therefore the working accuracy of the considered machine tool [6]. A significant proportion of workpiece errors are caused by thermally induced displacements $\delta$ of the TCP [7, 8]. In order to reduce thermal influences on the working accuracy of machine tools, both the development of energy efficient components with limited heat input and active cooling of relevant components are possible solutions [6]. The arrangement of the primary part as the significant heat source of LDD close to precision related machine tool components requires an active cooling to dissipate induced heat flow rates $\dot{Q}_{\text {ind }}$ [4]. Cooling systems for LDD are capable to ensure a nearly uniform temperature distribution along the precision related machine tool components and therefore reduce thermally induced displacements $\delta$ of the TCP [6]. Shabi et al. [6] state that the cooling system of a machine tool with LDD of type DMU80 eVo linear, DMG Mori AG, Bielefeld, Germany, causes $26 \%$ of the total energy consumption. Especially, auxiliary units for the supply and conditioning of fluidic media have been identified as significant energy consumers [9].

Due to the mentioned legal restrictions and increasing energy costs, there is a need for further increasing energy efficiency of high dynamic machine tools with LDD. In order to achieve this goal, a demand-oriented cooling system with a decentralised supply unit has been investigated [10]. It is proposed to provide the required cooling capacity $P_{\text {cool }}$ for each component by controlling the volumetric flow rate $\dot{V}$ instead of its temperature $\vartheta_{\text {cool }}$. This leads to a decoupling of thermal load and outlet temperature $\vartheta_{\text {out }}$, so that the temperature difference between outlet and inlet $\Delta \vartheta_{\text {out - in }}$ is maintained constant [10]. Due to the demandoriented supply of cooling capacity $P_{\text {cool }}$, the control of volumetric flow rate $\dot{V}$ is a promising approach to reduce the required total pump power $P_{\mathrm{p}}[10]$.

\section{SELF-COOLING SYSTEMS FOR LINEAR DIRECT DRIVES}

With the intention to overcome the area of conflict regarding productivity and energy efficiency of machine tools, a so called thermoelectric self-cooling (TSC)-system for LDD has been developed [11, 12]. The fundamental solution approach is based on integrating thermoelectric generators (TEG) between primary part of LDD and cooling system. Due to the TEG thermal conduction resistance $R_{\mathrm{TEG}}$, a temperature difference $\Delta \vartheta_{\mathrm{TEG}}$ arise between its outer surfaces as soon as the heat flow rate $\dot{Q}_{\text {TEG }}$ passes the TEG-arrangement. In this operating condition, TEG are capable to convert parts of the induced heat flow rate $\dot{Q}_{\text {ind }}$ into 
electrical energy $E$ [13]. The recuperated electrical power $P_{\text {el }}$ corresponds to the difference between the absorbed heat flow rate $\dot{Q}_{\mathrm{abs}, \mathrm{h}}$ and the emitted heat flow rate $\dot{Q}_{\mathrm{emi}, \mathrm{c}}$ on the hot and cold side of TEG, Fig. 1. The recuperated electrical power $P_{\mathrm{el}}$ is directly fed to the electrical consumers of the TSC-system. The utilisation of system-inherent energy $E_{\mathrm{inh}}$ to operate a cooling system has been first analysed by Martinez et al. [14, 15] and Kiflemariam et al. [16]. The feasibility of air and water cooled TSC-systems has been demonstrated for temperature control of electronic components such as processors.

In the shown energy harvesting concept, the electrical consumers of the TSC-system are only supplied by recuperated electrical power $P_{\mathrm{el}}$. An external power supply is not required. This TSC-system shows adaptive characteristics because the cooling capacity $P_{\text {cool }}$ is provided depending on induced heat flow rates $\dot{Q}_{\text {ind }}$, thus load-dependent and selfregulated [17]. Aiming for experimental analyses of the TSC-system, as well as proving its feasibility even under changing thermal loads, a self-designed machine tool is selected as demonstrator, Fig. 1.

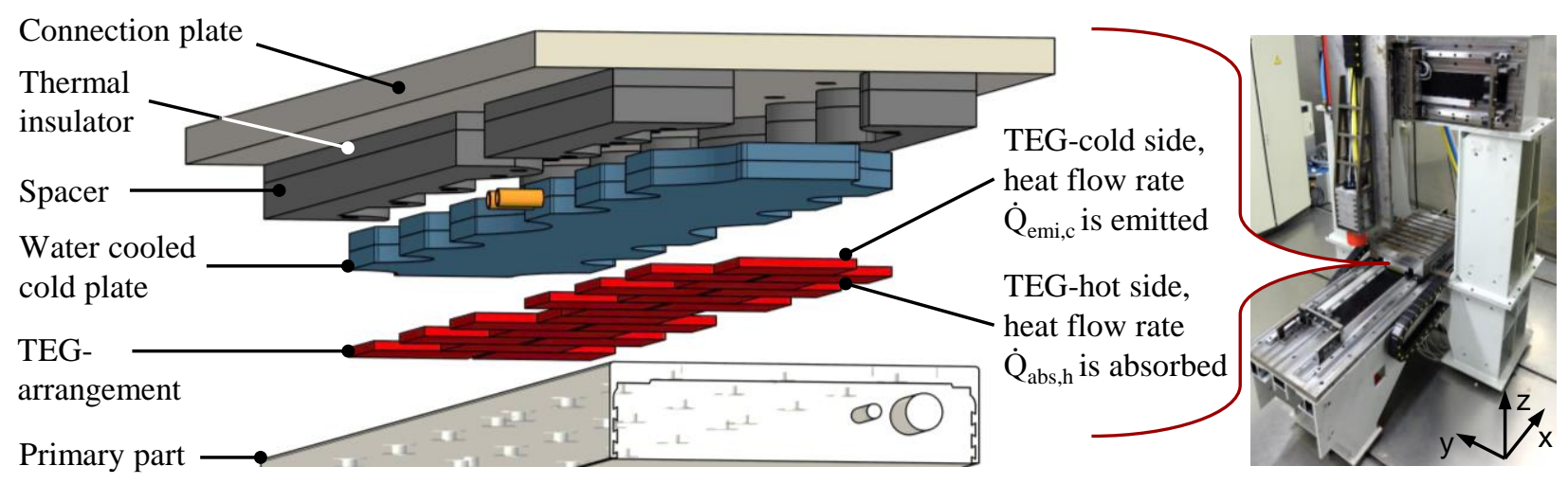

Fig. 1. Concept to integrate thermoelectric generators in a feed unit of a machine tool with LDD

The heat sink of the TSC-system is designed by a water cooled cold plate. Due to the adaptive system characteristics the volumetric flow rate $\dot{V}$ inside the cold plate is self-regulated by the recuperated electrical power $P_{\mathrm{el}}$ [17]. The considered $X$-axis of the selected machine tool demonstrator is equipped with a LDD of the type Al2830, marketed by Beckhoff Automation GmbH, Verl, Germany, without integrated cooling system. The designed TSC-system is placed on the upper surface of the primary part of the LDD, Fig. 1. To reduce the thermal contact resistances $R_{\text {cont }}$, the heat sink is pressed onto the TEG-arrangement by screws embedded in the connection plate. Four spacers are used to maintain the position of the primary part precisely even at high accelerations $a$ of the linear axis. The thermal insulators between connection plate and spacers are made of HP 2061 as a heat-insulating material. Hence, the induced heat flow rate $\dot{Q}_{\text {ind }}$ is forced through the TEG-arrangement. As a consequence, a temperature difference $\Delta \vartheta_{\text {TEG }}$ arises at TEG during operation of the LDD. In order to collect experimental data for model validation, the presented concept of a TSC-system has been prototypically realised, Fig. 2. Since the temperature gradient at TEG $\Delta \vartheta_{\mathrm{TEG}}$ determines the recuperated electrical power $P_{\mathrm{el}}$, and thus the resulting volumetric flow rate $\dot{V}$, the measurement of TEG-hot side temperature $\vartheta_{\mathrm{h}}$ is a necessary condition for model validation. Due to the internal structure of the primary part of LDD and 
its axial movement during operation, it is impossible to place thermocouples directly on the TEG-hot side. Because of this restriction a static test bench has been designed. Therefore, the primary part of LDD is replaced by a heating plate with cartridge heaters, which are operated by an adjustable power supply, Fig. 2 .

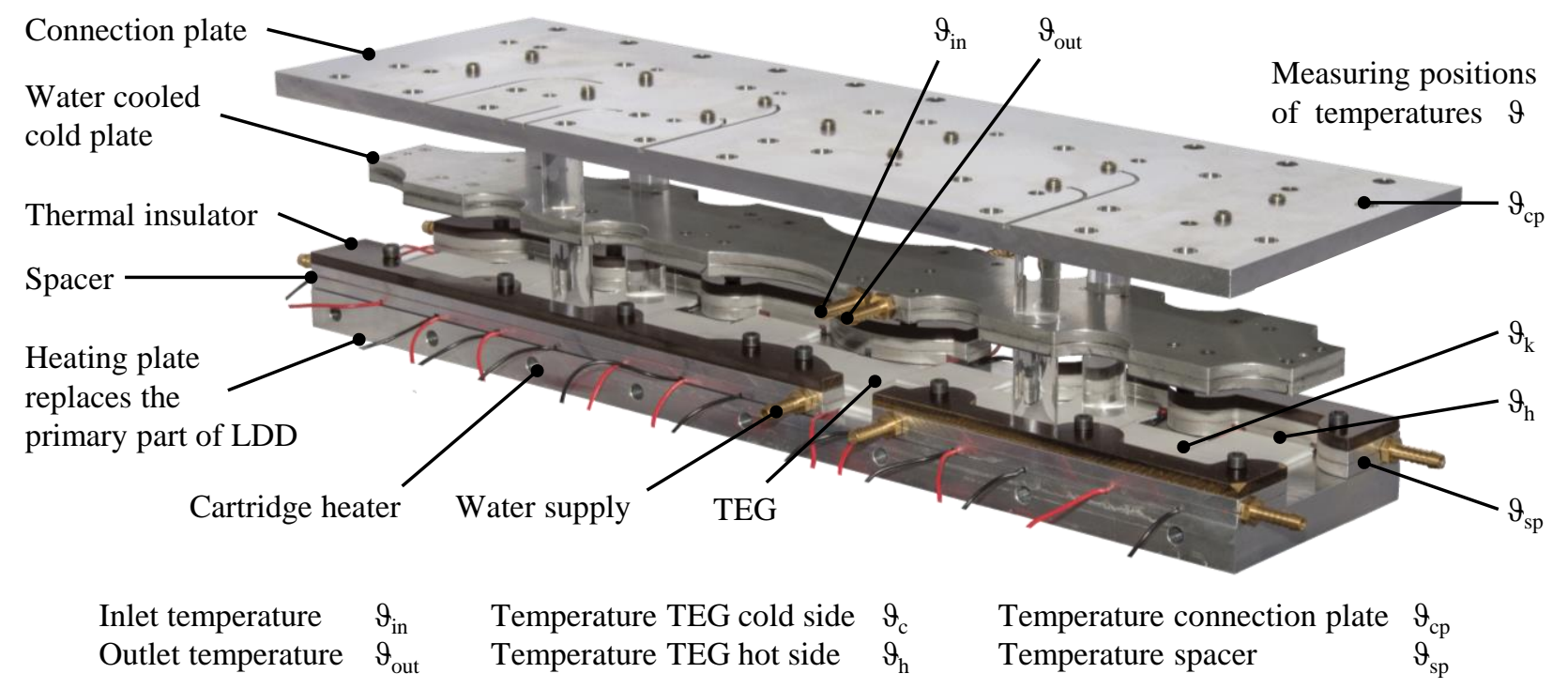

Fig. 2. Prototypically realised thermoelectric self-cooling system as a test bench for collecting experimental data

The set-up enables the imitation of the induced heat flow rates $\dot{Q}_{\text {ind }}$, previously measured in the machine tool demonstrator. Thus, the acquisition of relevant data is possible without axis movement and under controlled boundary conditions. During operation of the TSC-system, the recuperated electrical power $P_{\mathrm{el}}$ is directly fed to an electric parallel circuit consisting of a gear pump within a water cooling circuit and a fan of an adiabatic air cooling unit, Fig. 3.

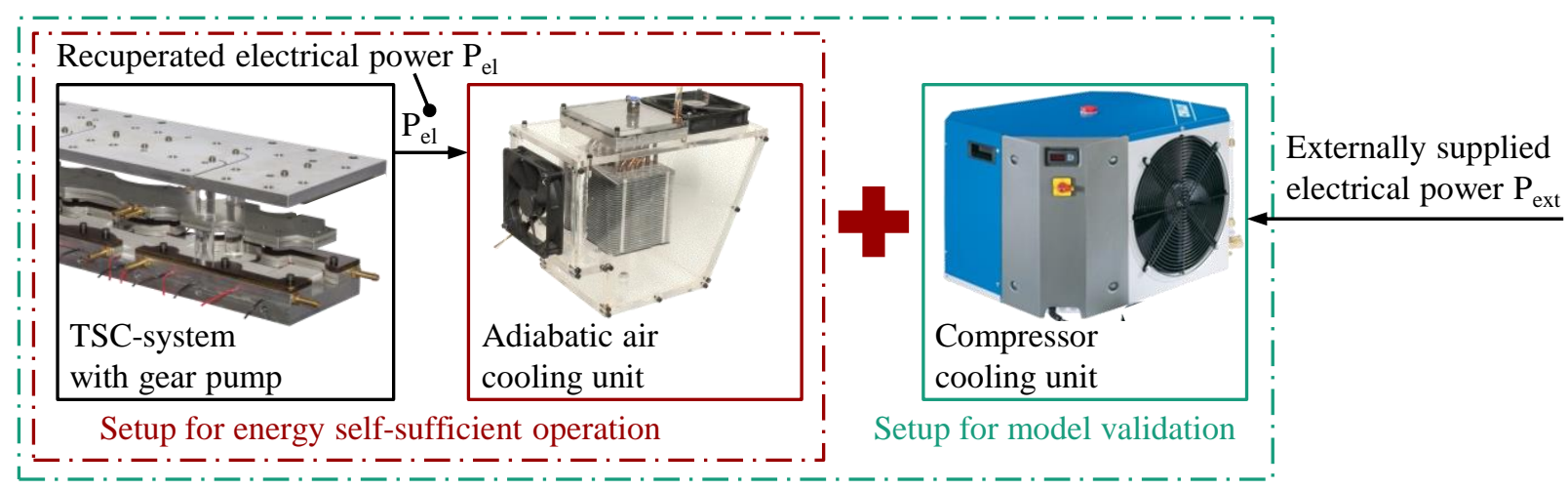

Fig. 3. Set-ups of the thermoelectric self-cooling system for energy self-sufficient operation and for model validation

Experimental results show that TEG are capable to recuperate sufficient electrical power $P_{\text {el }}$ to operate both electrical consumers. Thus, the feasibility of a fully energy self-sufficient operation is demonstrated. An essential condition to validate the subsequently 
derived model is a constant inlet temperature $\vartheta_{\text {in }}$ of the coolant during the entire test procedure. The adiabatic air cooling unit with a fan, only operated by TEG, is not capable to meet the mentioned condition. In order to achieve this goal, a compressor cooling unit with a two-point controller is additionally used, Fig. 3. This enables a control of the coolant temperature $\vartheta_{\text {in }}$ to a defined setpoint of $\vartheta_{\text {in }}=22^{\circ} \mathrm{C}$ with a hysteresis $H= \pm 0.7 \mathrm{~K}$. The temperature controlled coolant is taken from reservoir by the gear pump. Due to the additional use of the compressor cooling unit, the fan of the adiabatic air cooling unit operates without cooling function during the acquisition of experimental data for model validation. This set-up allows a model validation and thus the determination of model prediction accuracy $p$.

\section{MODELLING OF THERMOELECTRIC SELF-COOLING SYSTEMS}

Aiming for simulation-based design and analysis of TSC-systems a model to predict the thermoelectric behaviour has already been presented by Uhlmann et al. [17]. The model architecture is based on a thermal resistance network and has been implemented as a system simulation in MATLAB/Simulink, MathWorks, Natick, USA. The application of the used lumped-heat-capacity-method enables a one-dimensional investigation of steady-state and transient thermal behaviour. Supported by block libraries of the Simscape-toolbox the model is composed of the physical domains thermal, thermal-liquid, and electrical, which are in permanent interaction. The temperature-dependent parameters of TEG, the thermal conduction resistance $R_{\mathrm{TEG}}$, the electrical internal resistance $R_{\mathrm{i}}$ and the Seebeck-coefficient $\alpha$ are calculated as a function of the mean temperature $\vartheta_{\mathrm{m}}$ between hot and cold side of the semiconductor legs inside TEG. Stored in Simulink lookup tables, these parameters are updated in each time instant along the simulation time $t$. A detailed description of the modelling is given by Uhlmann et al. [17]. As a result, the already existing model is able to calculate the thermoelectric behaviour of a TSC-system in a small experimental set-up with six TEG of type TEG1-40-40-10, Eureca Messtechnik GmbH, Cologne, Germany. The comparison of simulative and experimental determined data for steady-state and transient conditions shows a high model prediction accuracy $p$ [17]. The lumped-heat-capacity method assumes that internal thermal conduction resistances $R_{\mathrm{cd}}$ of the investigated components are negligibly small in comparison to external thermal convection resistances $R_{\mathrm{cv}}$ between surfaces and fluids [18]. This ratio can be described by the Biot-number Bi, given by Eq. (1).

$$
B i=\frac{R_{\mathrm{cd}}}{R_{\mathrm{cv}}}
$$

The prerequisite for applying the lumped-heat-capacity method is fulfilled for a Biot-number of $B i<0.1$ [18]. Such systems are idealised, because temperature gradients $\Delta \vartheta$ in the components must exist for heat conduction. The method should therefore only be used to simulate the thermal behaviour of systems with an approximately homogeneous temperature distribution in the modelled components. If the Biot-number Bi reaches values of $B i \geq 0.1$, negative influences on the prediction accuracy $p$ of the model are expected. In the already existing model, introduced by Uhlmann et al. [17], all components are therefore 
insulated from the environment. In the now presented research, the described model is scaled-up to the geometrically possible solution space in the machine tool demonstrator equipped with LDD, Fig. 1. It is investigated, if a model with a comparable architecture allows the prediction of thermoelectric behaviour even without thermal insulation from the environment. The main components of the designed TSC-system are represented by a thermal resistance network, Fig. 4.

The thermal system behaviour is derived by a mesh of representative nodes, each one connected to the surrounding nodes by a thermal resistance $R$ and endowed with a thermal capacity $C$. In Fig. 4, only thermal conduction resistances $R_{\mathrm{cd}}$ and the thermal convection resistance $R_{\text {cool }}$ to the coolant are displayed. The model also uses thermal convection resistances $R_{\mathrm{cv}}$ between the main components and the environment. The thermal resistance network consist of six main components. In accordance with the conceptual illustration in Fig. 1 and the realised system in Fig. 2, the visualisation of the derived model is symmetrical to the centerline, Fig. 4 . The thermal conduction resistances of the connection plate $R_{\mathrm{cp}}$, the thermal insulators $R_{\mathrm{insu}}$, the spacers $R_{\mathrm{sp}}$, the heating plate $R_{\mathrm{hp}}$ and the thermal convection resistance $R_{\text {cool }}$ are therefore shown divided. As a model simplification, the mentioned thermal resistances $R$ are merged. In addition, the 19 installed TEG are combined to form a substitute component. Thereby, temperature differences $\Delta \vartheta$ between different TEG and increasing cooling water temperatures $\vartheta_{\text {cool }}$ are neglected. The thermal conduction resistances $R_{\mathrm{cd}}$ of all modelled components are calculated based on the geometry and the thermal conductivity $\lambda$ and are hereinafter termed as thermal resistances $R$. The thermal capacities $C$ are determined considering masses $m$ and specific heat capacities $c$ of the used materials.

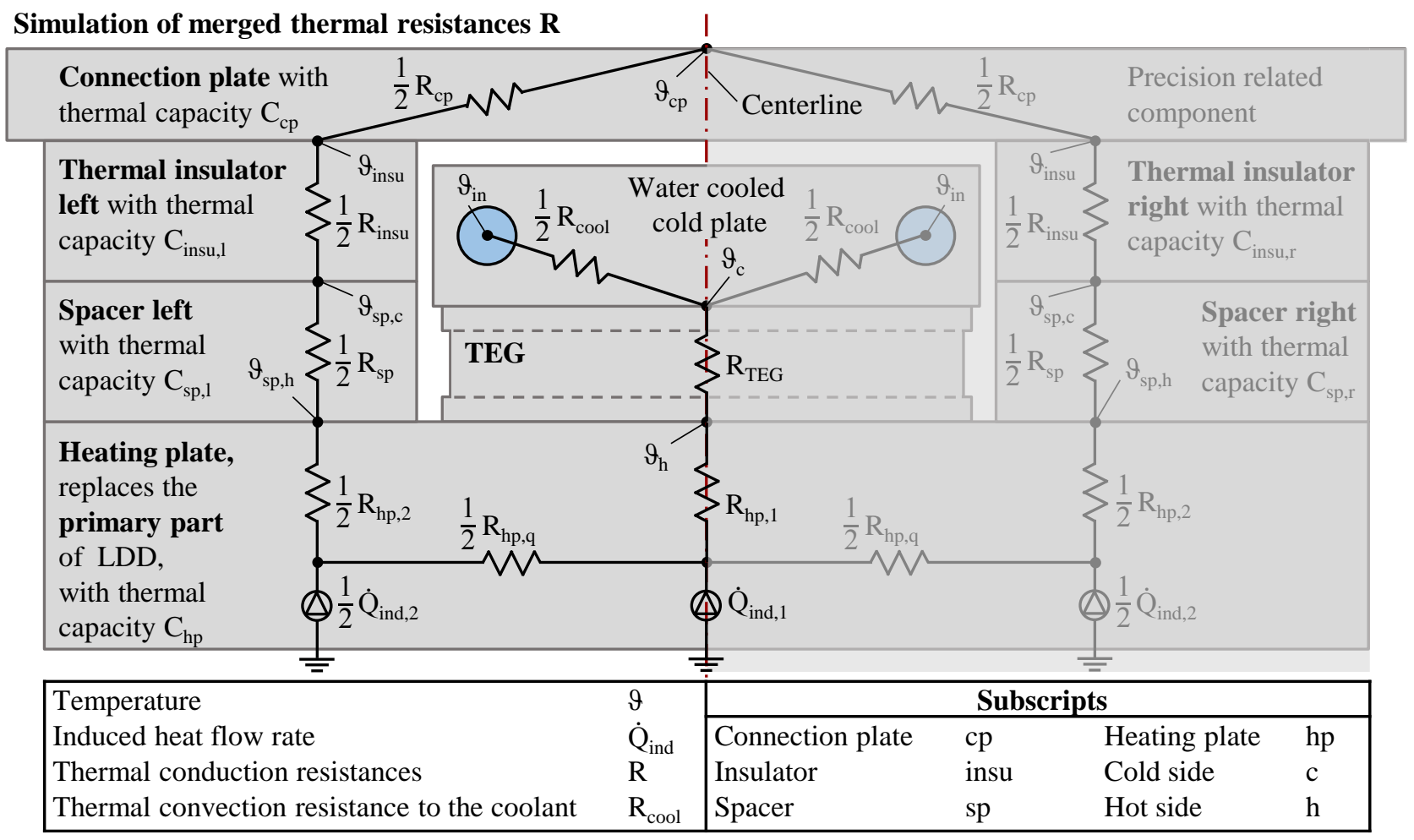

Fig. 4. Thermal resistance network for simulation of a thermoelectric self-cooling system for linear direct drives 
Supported by ideal heat sources from the Simscape library equal heat flow rates $\dot{Q}_{\text {ind }} / 2$ are induced in the nodes of the heating plate. The amounts correspond to the values previously measured in the machine tool demonstrator at typical load profiles as well as maximum possible induced heat flow rates $\dot{Q}_{\text {ind }}$ of the used LDD. The resulting two heat flow paths are only connected by the thermal resistance $R_{\mathrm{hp}, \mathrm{q}}$ inside the heating plate. The amount of heat flow rate $\dot{Q}$ within these heat flow paths is determined by the adjacent thermal resistances $R$. Aiming for a constant temperature in the precision-related connection plate $\vartheta_{\mathrm{cp}}$, the heat flow rate $Q_{\mathrm{cp}}$ through the spacer is reduced as much as possible by the adjacent thermal insulators. Thus, a major share of the induced heat flow rate $\dot{Q}_{\text {ind }}$ is forced through the modelled TEG-arrangement. As a consequence, a temperature difference $\Delta \vartheta_{\text {TEG }}$ arises during operation. This value is significantly influenced by the thermal resistance of the TEG-arrangement $R_{\text {TEG, }}$ which is calculated in the thermal subsystem, Fig. 5.

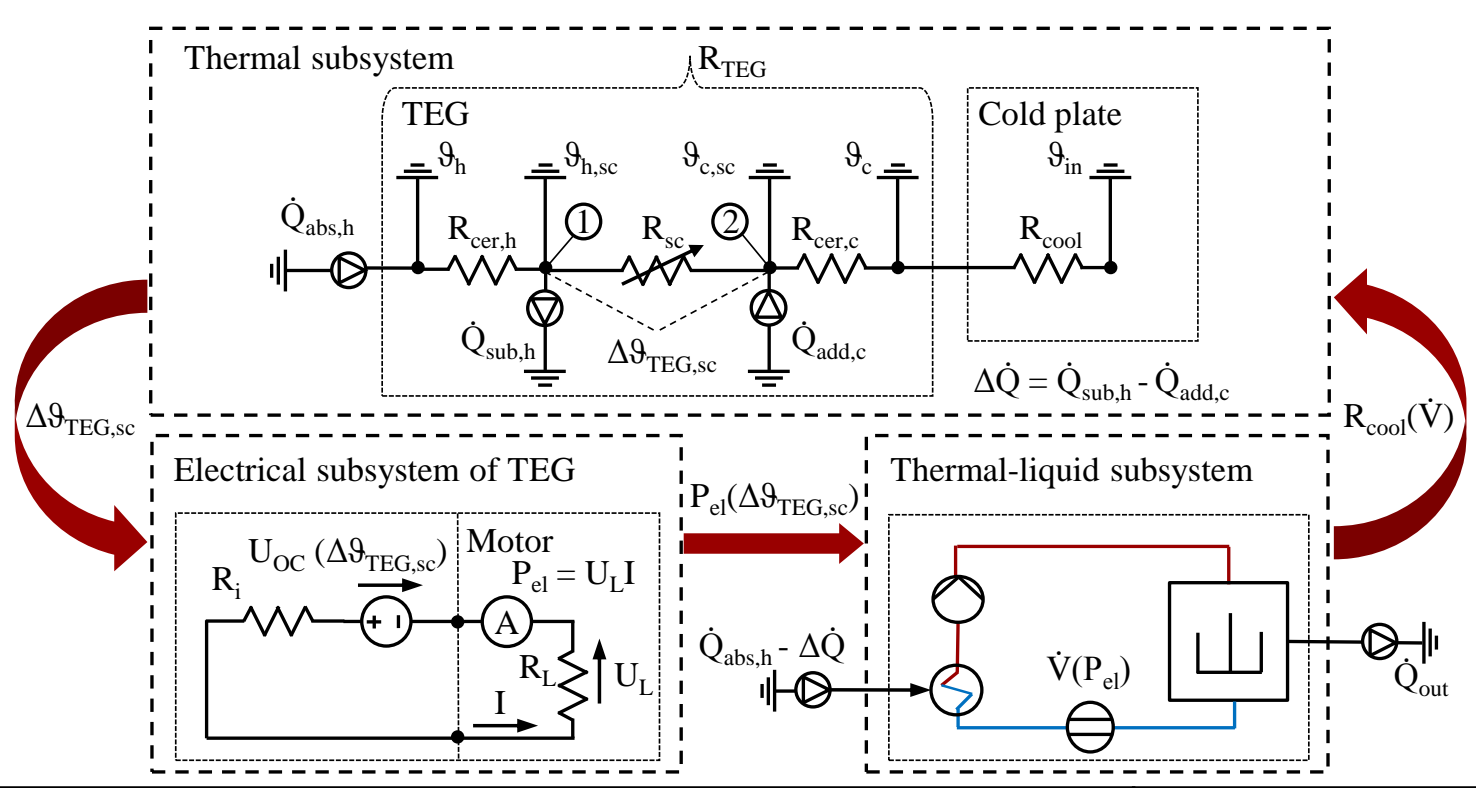

\begin{tabular}{|llll|ll|}
\hline Electrical internal resistance & $\mathrm{R}_{\mathrm{i}}$ & Load current & $\mathrm{I}$ & \multicolumn{2}{|c|}{ Subscripts } \\
\cline { 5 - 7 } Electrical load resistance & $\mathrm{R}_{\mathrm{L}}$ & Recuperated electrical power & $\mathrm{P}_{\text {el }}$ & Ceramic & cer \\
Open-circuit & $\mathrm{U}_{\mathrm{OC}}$ & Volumetric flow rate & $\mathrm{V}$ & Semiconductor & sc \\
Load voltage & $\mathrm{U}_{\mathrm{L}}$ & Heat flow rate & $\dot{\mathrm{Q}}$ & Absorbed & abs \\
Temperature & $\vartheta$ & Thermal conduction resistance & $\mathrm{R}$ & Emitted & emi \\
Temperature difference & & Thermal convection & & Subtracted & sub \\
at the semiconductor layer & $\Delta \vartheta_{\text {TEG,sc }}$ & resistance to the coolant & $\mathrm{R}_{\text {cool }}$ & Added & add \\
\hline Hot side & $\mathrm{h}$ & Cold side & $\mathrm{c}$ & Output & out \\
\hline
\end{tabular}

Fig. 5. Model structure for simulation of thermoelectric self-cooling systems

The thermal resistance of the TEG-arrangement $R_{\text {TEG }}$ consists of two thermal resistances $R_{\mathrm{cer}, \mathrm{h} / \mathrm{c}}$ representing the ceramic plates of TEG and a temperature dependent thermal resistance $R_{\mathrm{sc}}$ which represents the semiconductor legs of the 19 TEG. Aiming for model simplification, the semiconductor legs are replaced by a homogeneous layer. To determine the thermal resistance of the TEG-arrangement $R_{\mathrm{TEG}}$ and the temperature difference between the outer surfaces of the semiconductor layer $\Delta \vartheta_{\mathrm{TEG}, \mathrm{sc}}$, the energy balances 
at nodes number 1 and 2 have to be calculated. The in- and outgoing heat flow rates $\dot{Q}$ are determined considering the temperature dependent thermal resistance $R_{\mathrm{sc}}$ and the thermoelectric effects Seebeck, Peltier and Joule. A simulation of the thermoelectric system behaviour requires a calculation for each time instant. The thermoelectric Thomson-effect is neglectable for the respective application and thus not considered.

The absorbed heat flow rate $\dot{Q}_{\mathrm{abs}, \mathrm{h}}$ at the hot side of the semiconductor layer (node 1 in Fig. 5) is given by Eq. (2) and (3).

$$
\begin{gathered}
\dot{Q}_{\mathrm{abs}, \mathrm{h}}=\dot{Q}_{\mathrm{P}, \mathrm{h}}+\dot{Q}_{\mathrm{cd}}-\frac{1}{2} \dot{Q}_{\mathrm{J}} \\
\dot{Q}_{\mathrm{abs}, \mathrm{h}}=\alpha I \vartheta_{\mathrm{h}}+\lambda\left(\vartheta_{\mathrm{h}}-\vartheta_{\mathrm{c}}\right)-\frac{1}{2} R_{\mathrm{i}} I^{2}
\end{gathered}
$$

where: $\lambda$ - Thermal conductivity, $\alpha$ - Seebeck coefficient, $\dot{Q}_{\mathrm{J}}-$ Heat flow rate, added by Joule-effect on the hot and cold side of semiconductor layer, $\dot{Q}_{\mathrm{cd}}-$ Heat flow rate, due to heat conduction inside semiconductor layer, $\dot{Q}_{\mathrm{P}, \mathrm{h}}-$ Heat flow rate, subtracted by Peltier-effect from the hot side of semiconductor layer, $\dot{Q}_{\mathrm{P}, \mathrm{c}}-$ Heat flow rate, added by Peltier-effect on the cold side of semiconductor layer. The emitted heat flow rate $\dot{Q}_{\mathrm{emi}, \mathrm{c}}$ at the cold side of the semiconductor layer (node 2 in Fig. 5) is given by Eq. (4) and (5).

$$
\begin{gathered}
\dot{Q}_{\mathrm{emi}, \mathrm{c}}=\dot{Q}_{\mathrm{P}, \mathrm{c}}+\dot{Q}_{\mathrm{cd}}+\frac{1}{2} \dot{Q}_{\mathrm{J}} \\
\dot{Q}_{\mathrm{emi}, \mathrm{c}}=\alpha I \vartheta_{\mathrm{c}}+\lambda\left(\vartheta_{\mathrm{h}}-\vartheta_{\mathrm{c}}\right)+\frac{1}{2} R_{\mathrm{i}} I^{2}
\end{gathered}
$$

The heat flow rate $\dot{Q}_{\text {sub,h, }}$ subtracted in node 1, displayed in Fig. 5, is given by Eq. (6).

$$
\dot{Q}_{\text {sub,h }}=\dot{Q}_{\mathrm{P}, \mathrm{h}}-\frac{1}{2} \dot{Q}_{\mathrm{J}}
$$

The heat flow rate $\dot{Q}_{\text {add,c }}$, added in node 2, displayed in Fig. 5, is given by Eq. (7).

$$
\dot{Q}_{a d d, \mathrm{c}}=\dot{Q}_{\mathrm{P}, \mathrm{c}}+\frac{1}{2} \dot{Q}_{\mathrm{J}}
$$

The difference between absorbed heat flow rate $\dot{Q}_{\text {abs,h }}$ and emitted heat flow rate $\dot{Q}_{\text {emi,c }}$ corresponds to the electrical power $P_{\text {el }}$ recuperated by TEG and is given by Eq. (8).

$$
\Delta \dot{Q}=\dot{Q}_{\mathrm{abs}, \mathrm{h}}-\dot{Q}_{\mathrm{emi}, \mathrm{c}}=\alpha I\left(\vartheta_{\mathrm{h}}-\vartheta_{\mathrm{c}}\right)-\dot{Q}_{\mathrm{J}}=P_{\mathrm{el}}
$$

The emitted heat flow rate $\dot{Q}_{\text {emi,c }}$ is dissipated by the adjacent water cooling system. It is modelled by the thermal-liquid domain of Simscape, Fig. 5. The thermal resistance between water cooled cold plate and coolant $R_{\text {cool }}$ is calculated on the basis of the tube surface area $A$ and the convective heat transfer coefficient $h$, which is given for a defined Nusselt number $N u$. The output parameters of the thermal-liquid subsystem are the coolant temperature $\vartheta_{\text {out }}$ at the outlet and the current value of the thermal convection resistances $R_{\text {cool }}$ depending on the volumetric flow rate $\dot{V}$. The calculated temperature differences between the hot and cold side of the semiconductor layer $\Delta \vartheta_{\mathrm{TEG}, \mathrm{sc}}$ is transferred to the electrical subsystem, which is modelled in the electrical domain of Simscape, Fig. 5. The recuperated electrical power $P_{\mathrm{el}}$ is directly fed to the motor of water pump and to the fan of adiabatic air cooling unit. The model is capable of simulating both, steady and transient states of the TSC-system. 
Therefore, open-circuit $U_{\mathrm{OC}}$, load voltage $U_{\mathrm{L}}$, load current $I$, recuperated electrical power $P_{\mathrm{el}}$, and all heat flow rates by Peltier $\left(\dot{Q}_{\mathrm{P}}\right)$ - and Joule-effect $\dot{Q}_{\mathrm{J}}$ are calculated.

\section{MODEL VALIDATION}

In order to validate the simulative results, the already presented test bench has been used to collect experimental data, Fig 2. The output parameters to determine the model prediction accuracy $p$ are the TEG-hot side temperature $\vartheta_{\mathrm{h}}$, the TEG-cold side temperature $\vartheta_{\mathrm{c}}$, the tempe-rature under the spacer $\vartheta_{\mathrm{sp}}$, the coolant outlet temperature $\vartheta_{\text {out }}$, the recuperated electrical power $P_{\mathrm{el}}$ as well as the volumetric flow rate $\dot{V}$. These parameters are of main relevance for the performance and operability of the investigated TSC-system. The positions of the installed thermocouples for temperature measurement are shown, Fig. 6.

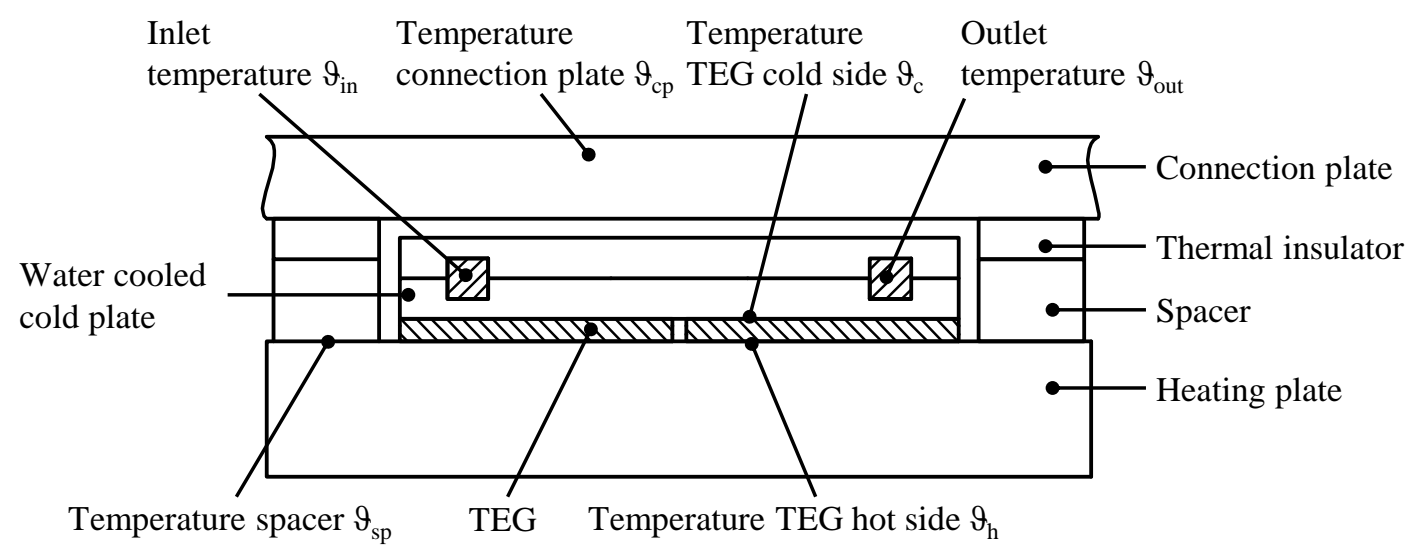

Fig. 6. Positions of the installed thermocouples for temperature measurement

\subsection{VALIDATION BASED ON A STARTING PROCESS OF THE TSC-SYSTEM}

To assess the transient model prediction accuracy $p$, a starting process of the TSCsystem is simulated. Therefore, a constant heat flow rate of $\dot{Q}_{\text {ind }}=1,060 \mathrm{~W}$ is induced, which corresponds to the maximum possible amount of the later used primary part, Fig. 7a. The temperature under the spacer $\vartheta_{\text {sp }}$ shows the highest determined values, and allows therefore an evaluation regarding a possible overheating. The experimentally and simulatively determined temperatures $\vartheta_{\text {sp }}$ rise with the time $t$ and reach a thermal steady state at a time of $t \geq 1,400 \mathrm{~s}$ with an absolute temperature of $\vartheta_{\mathrm{sp}, \mathrm{sim}}=67.0^{\circ} \mathrm{C}$, Fig. $7 \mathrm{~b}$. The maximum error $e$ between measured and simulated values is $e\left(\vartheta_{\mathrm{sp}}\right)=0.5 \mathrm{~K} \hat{=1.0 \%}$ at the time of $t=590 \mathrm{~s}$. With rising temperature on TEG-hot side $\vartheta_{\mathrm{h}}$, the difference between TEG-hot and cold side temperature $\Delta \vartheta_{\mathrm{h}-\mathrm{c}}$ also increases. The maximum error $e$ between measured and simulated values is $e\left(\Delta \vartheta_{\mathrm{h}-\mathrm{c}}\right)=0.7 \mathrm{~K} \triangleq 2.7 \%$ at the time $t=680 \mathrm{~s}$. The temperature difference $\Delta \vartheta_{\mathrm{h}-\mathrm{c}}$ determines the amount of recuperated electrical power $P_{\mathrm{el}}$ and thus the operating ability of the water pump. At time $t \geq 12 \mathrm{~s}$ the water pump is operating and supplies the cold plate with an increasing volumetric flow rate $\dot{V}$, Fig. 7c. 

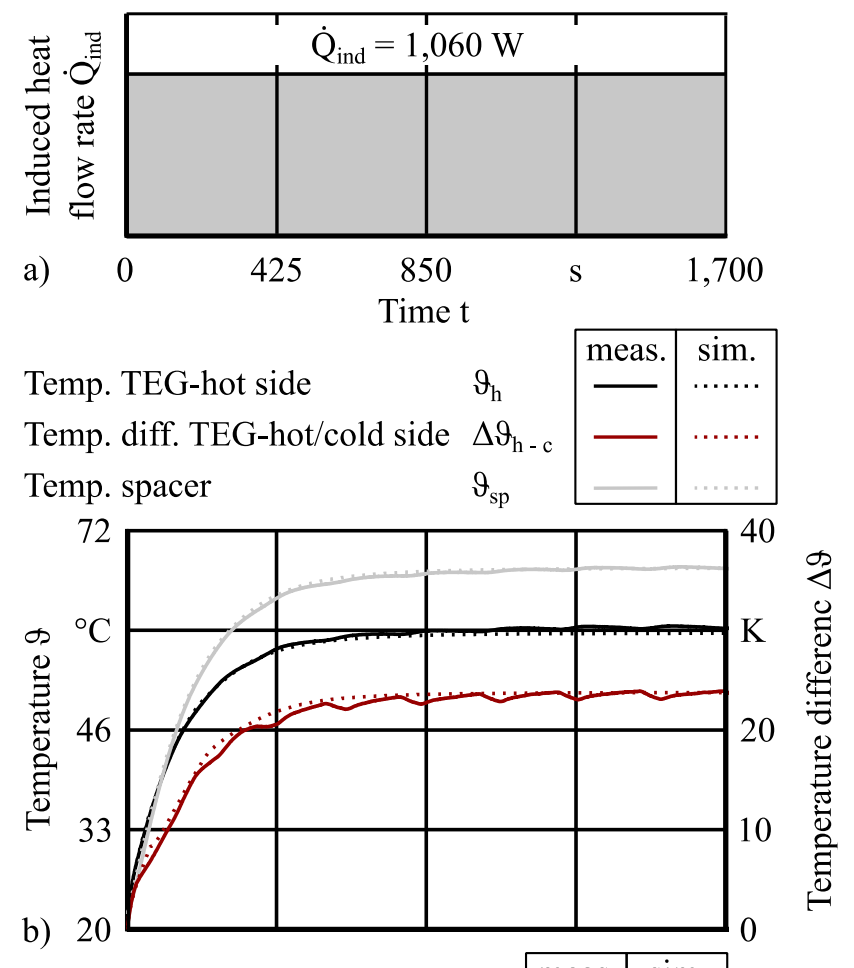

b) 20

c) 0.0

Volumetric flow rate $\dot{\mathrm{V}}$

Electrical power
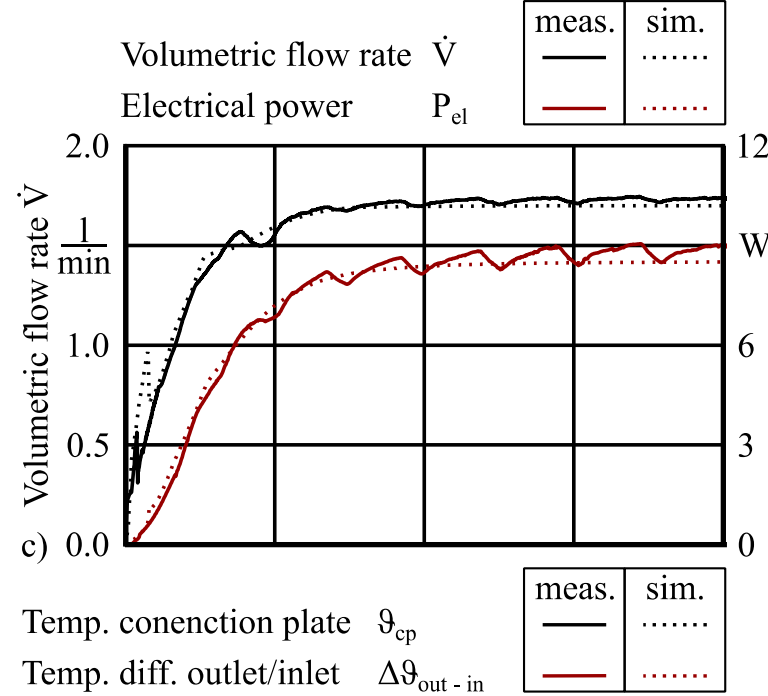

Temp. diff. outlet/inlet $\Delta \vartheta_{\text {out - in }}$

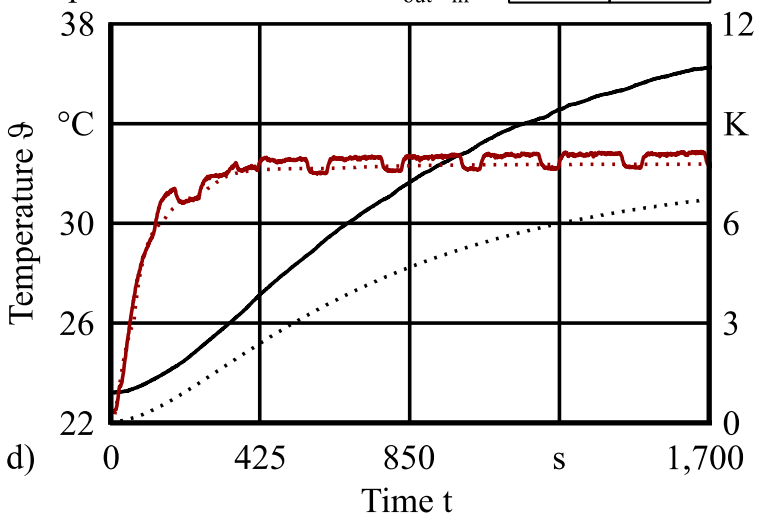

Fig. 7. Simulated and experimental results during a starting process of the TSC-system:

a) Induced heat flow rate $\dot{Q}_{\text {ind }}$; b) System-determining temperatures $\vartheta_{\text {sys }}$; c) Volumetric flow rate $\dot{V}$ and electrical power $P_{\mathrm{el}}$; d) Temperatures to evaluate the performance of the TSC-system $\vartheta_{\text {eva }}$ 
The maximum error $e$ between measured and simulated values is $e(\dot{V})=0.4 \mathrm{l} / \mathrm{min} \hat{=} 40 \%$ at time $t=64 \mathrm{~s}$. Except this significant deviation shortly after starting, a high correlation between measured and simulated values is found. In addition, the simulated values of the temperature difference between outlet and inlet $\Delta \vartheta_{\text {out - in }}$ show a high correspondence to the experimental results. The major deviations of this model validation is found at the temperature on the upper surface of the connection plate $\vartheta_{\mathrm{cp}}$. The maximum error $e$ between measured and simulated values is $e\left(\vartheta_{\mathrm{cp}}\right)=5 \mathrm{~K} \triangleq 14.6 \%$ at time $t=1,700 \mathrm{~s}$. At this time the temperatures $\vartheta_{\text {cp }}$ has not reached a thermal steady-state.

\subsection{VALIDATION BASED ON A TIME-VARYING THERMAL LOAD PROFILE}

To assess the transient model prediction accuracy $p$ under variable boundary conditions, a thermal load profile has been induced in the test bench, Fig. 8a. The depicted heat flow rates $\dot{Q}_{\text {ind }}$ have been calculated using the previously measured motor currents $I_{\mathrm{M}}$ inside the primary part of LDD during typical motion profiles of the feed unit. As soon as the components beneath the thermal insulator are reaching thermal steady-state, the induced heat flow rates $\dot{Q}_{\text {ind }}$ were abruptly changed by an adjustable power supply, Fig. 8a. The reduction of the induced heat flow rate to $\dot{Q}_{\text {ind }}=200 \mathrm{~W}$ at the time $t=285 \mathrm{~s}$ leads to a decrease of the measured and simulated temperature TEG-hot side $\vartheta_{\mathrm{h}}$, Fig. $8 \mathrm{~b}$. The maximum error $e$ between measured and simulated values is $e\left(\Delta \vartheta_{\mathrm{h}}\right)=1.0 \mathrm{~K} \triangleq 2.7 \%$ at time $t=5,600 \mathrm{~s}$. With this change, the temperature difference between TEG-hot and cold side $\Delta \vartheta_{\mathrm{h}-\mathrm{c}}$ also decreases. This correlation is valid for the entire time interval $285 \mathrm{~s} \leq t \leq 5,600 \mathrm{~s}$.

Due to the direct dependence between temperature difference $\Delta \vartheta_{\mathrm{h}-\mathrm{c}}$ and recuperated electrical power $P_{\mathrm{el}}$, an adaptive adjustment of the volumetric flow rate $\dot{V}$ is found for the entire time interval, Fig. 8c. The maximum error $e$ between measured and simulated values of recuperated electrical power $P_{\mathrm{el}}$ is $e\left(P_{\mathrm{el}}\right)=0.6 \mathrm{~W} \triangleq 6.6 \%$ at the time of $t=5,600 \mathrm{~s}$. In addition, also the volumetric flow rate $\dot{V}$ shows a slight error $e$ between measured and simulated values of $e(\dot{V})=0.041 / \mathrm{min} \triangleq 2.3 \%$.

The investigation shows that the TSC-system adaptively regulates the cooling capacity $P_{\text {cool }}$ by adjusting the volumetric flow rate $\dot{V}$ without closed-loop control. Due to this demand-oriented supply of volumetric flow rate $\dot{V}$, the temperature difference between outlet and inlet $\Delta \vartheta_{\text {out -in }}$ shows only slight variations $\Delta \vartheta_{\text {out-in,sim }}(t)=2.3 \mathrm{~K}$ for the entire time interval, Fig. 8 d.

The simulated values of the temperature difference between outlet and inlet $\Delta \vartheta_{\text {out }- \text { in }}$ show a high correspondence to the experimentally collected values. The maximum error $e$ between measured and simulated values is $e\left(\Delta \vartheta_{\text {out }- \text { in }}\right)=0.5 \mathrm{~K} \hat{=} 6.0 \%$ at the time of $t=2,000 \mathrm{~s}$. The major deviations of this model validation, based on a time-varying thermal load profile, is found considering the temperatures on the upper surface of the connection plate $\vartheta_{\text {cp. }}$. The maximum error $e$ between measured and simulated values is $e\left(\vartheta_{\mathrm{cp}}\right)=6.9 \mathrm{~K} \triangleq 17.8 \%$ at the time $t=5,600 \mathrm{~s}$. Additionally, the results show that no thermal steady-state has been achieved in the connection plate at the time $t=5,600 \mathrm{~s}$, so that an increasing error $e$ will be observed at time of $t>5,600 \mathrm{~s}$. 

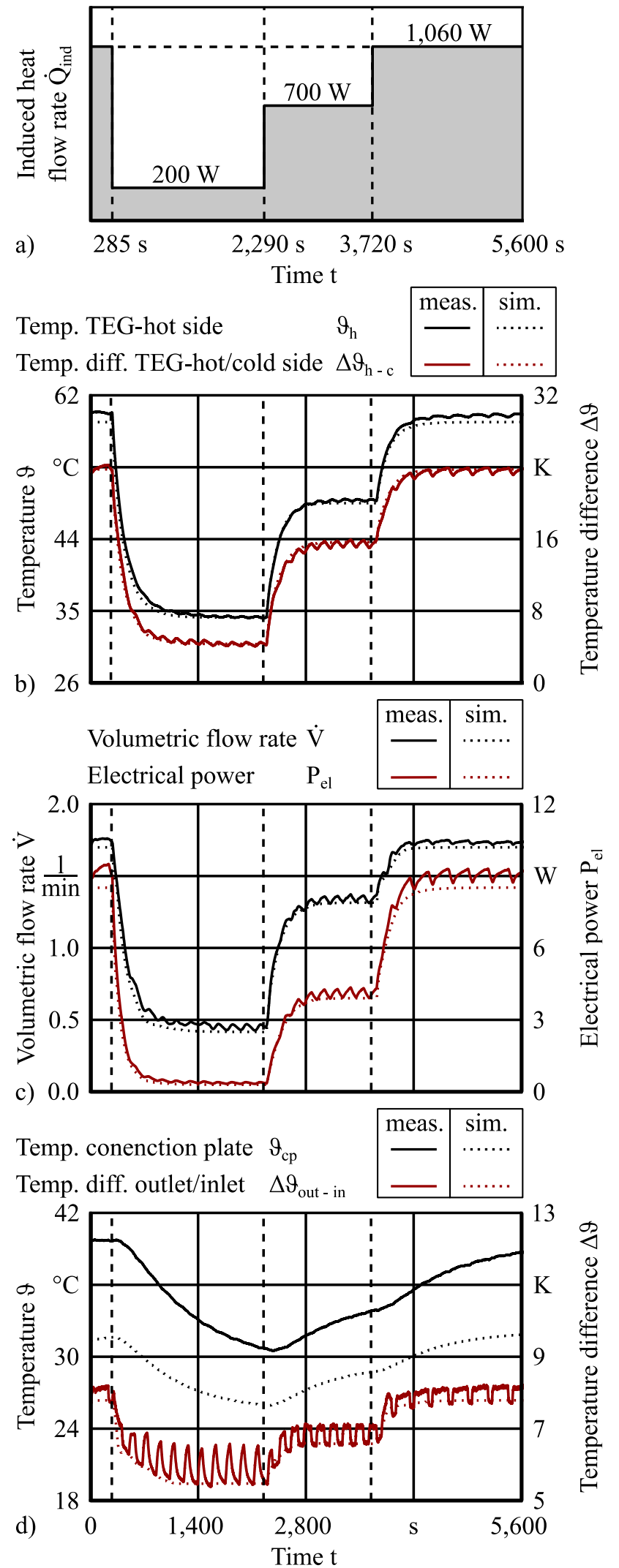

Fig. 8. Simulated and experimental results during a time-varying thermal load profile: a) Induced heat flow rate $\dot{Q}_{\text {ind; }}$ b) System-determining temperatures $\vartheta_{\text {sys }}$; c) Volumetric flow rate $\dot{V}$ and electrical power $P_{\text {el }}$;

d) Temperatures to evaluate the performance of the TSC-system $\vartheta_{\text {eva }}$ 


\subsection{DISCUSSION AND ANALYSIS}

Referring to the introduction, a demand-oriented cooling system with a coolant volume flow control and decentralised water pumps has been proposed [10]. Due to a decoupling of thermal load and outlet temperature $\vartheta_{\text {out }}$, this approach offers the potential to ensure a nearly constant temperature difference between outlet and inlet $\Delta \vartheta_{\text {out - in, even with changing thermal }}$ loads [10]. This characteristic of a cooling system is considered positive because it supports the maintenance of a thermal steady-state in the heat sink and the adjacent machine tool components.

The results of the now presented research reveal that such a volume flow controlled cooling system is realisable without closed-loop control and moreover energy self-sufficient. The developed TSC-system is capable to provide a demand-oriented volumetric flow rate $\dot{V}$, which increases with rising induced heat flow rates $\dot{Q}_{\text {ind }}$. Due to these adaptive characteristics, the results of the temperature difference between outlet and inlet $\Delta \vartheta_{\text {out - in }}$ show only minor variations. Therefore, the results imply promising prospects to maintain a constant outlet temperature $\vartheta_{\text {out }}$ without external energy supply. With this goal, further research efforts are intended.

Regarding to the derived model, a high prediction accuracy $p$ is revealed. With exception of the connection plate, the error $e$ between experimentally and simulatively acquired results is calculated to $e \leq 10 \%$, even for changing thermal loads. Referring to the already defined Biot-number $\mathrm{Bi}$, the internal thermal conduction resistances $R_{\mathrm{cd}}$ of the connection plate seems to be not negligible small comparing to the external thermal convection resistances $R_{\mathrm{cv}}$. The mentioned parameters have not been quantified, but the model prediction accuracy $p$ is therefore negatively influenced. Due to the direct connection to the machine tool slide, increasing temperatures of the connecting plate $\vartheta_{\text {cp }}$ with thermally induced deformations $\Delta l$ could cause negative influences on the working accuracy of the machine tool demonstrator. With the goal of increasing prediction accuracy $p$ of the presented model, and to calculate the resulting thermally induced deformations $\Delta l$, further research efforts regarding modelling of TSC-systems are focused.

\section{SUMMARY AND OUTLOOK}

In the area of conflict between accuracy, productivity and energy efficiency, machine tools are faced with contrasting requirements. The application of linear direct drives provides the potential for highly productive manufacturing, combined with the achievement of continuously rising demands for working accuracy of machine tools. Energy related research identifies cooling systems as significant energy consumers of machine tools.

To reduce the required energy demand, a thermoelectric self-cooling system for linear direct drives is presented. Based on an energy harvesting concept, the pump of a water cooling circuit and the fan of an adiabatic air cooling unit are only supplied by electrical power, which is recuperated by thermoelectric generators. In the now presented research, a model to predict the thermoelectric behaviour and to calculate the cooling performance is derived. Aiming for 
model validation, a static test bench has been put into operation. This enables an acquisition of experimental data under controlled boundary conditions. Therefore, the previously in the machine tool demonstrator measured heat flow rates are imitated by a heating plate.

For steady-state and transient conditions a high prediction accuracy of the derived model is determined. Thus, the model is accurate enough to be used as a powerful tool for development, analysing and optimisation of water flow thermoelectric self-cooling systems. Supported by the derived model an optimisation as well as a subsequent integration into the machine tool demonstrator have been realised, Fig. 9. The experimental investigation of a thermoelectric self-cooling system, integrated in the machine tool demonstrator, is one current research topic at the Institute for Machine Tools and Factory Management (IWF). Further research activities are intended to overcome the area of conflict between accuracy, productivity and energy efficiency of machine tools.

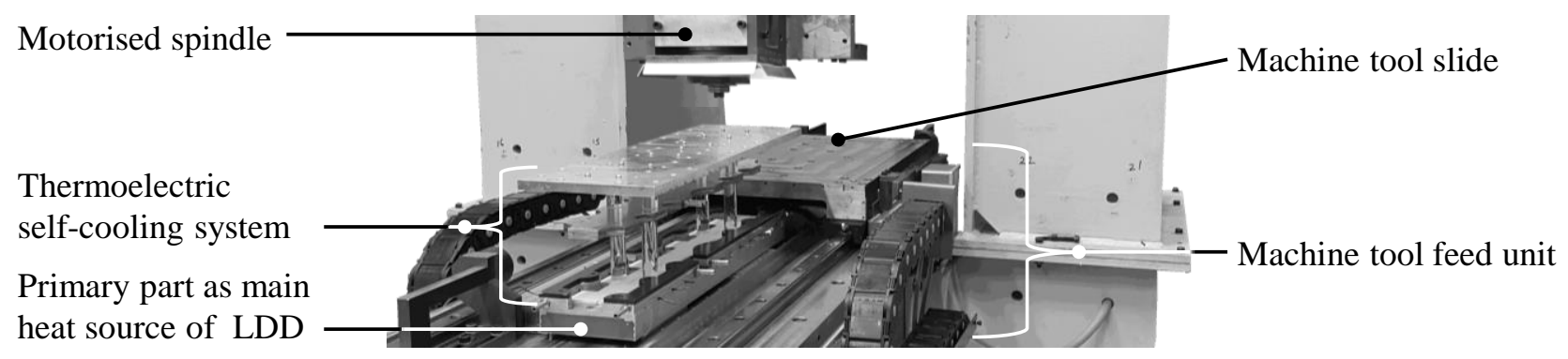

Fig. 9. Prototypical integration of the thermoelectric self-cooling system into the machine tool demonstrator

\section{ACKNOWLEDGMENT}

This research was funded by the German Research Foundation (DFG). The title of the research project is "Concepts for energy self-sufficient cooling of linear direct drives".

[1] KINKEL S., LAY G., 2006, Technologietrends in der Produktion: Praxis der Anlagenmodernisierung in der deutschen Metall- und Elektroindustrie, Bulletins, German Manufacturing Survey, 39, 1-12.

[2] The European Parliament and the Council of the European Union, 2009, Directive 2009/125/EC of the European Parliament and of the Council of 21 October 2009: establishing a framework for the setting of ecodesign requirements for energy-related products, Official Journal of the European Union, 52/L285, 10-35.

[3] GROßMANN K., 2015, Thermo-energetic Design of Machine Tools, Springer, Cham Heidelberg New York Dordrecht London.

[4] ALTINTAS Y., VERL A., BRECHER C., URIARTE L., PRITSCHOW G., 2011, Machine tool feed drives, CIRP Annals, 60/2, 779-796.

[5] TANABE I., DE SOUSA GAMA V., ISE Y., TAKAHASHI S., ISOBE H., 2019, Development of a High-Speed Mirror-Like Finish Polishing Technology for Minute Parts Based on a Linear Motor, Journal of Machine Engineering, 19/1, 71-85.

[6] SHABI L., WEBER J., WEBER J., 2017, Analysis of the Energy Consumption of Fluidic Systems in Machine Tools, Procedia CIRP, 63, 573-579. 
[7] MAYR J., JEDRZEJEWSKI J., UHLMANN E., DONMEZ M.A., KNAPP W., HÄRTIG F., WENDT K., MORIWAKI T., SHORE P., SCHMITT R., BRECHER C., WÜRZ T., WEGENER K., 2012, Thermal issues in machine tools, CIRP Annals - Manufacturing Technology, 61/2, 771-791.

[8] MARES M., HOREJS O., HORNYCH J., 2015, Advanced Thermal Error Compensation of a Floor Type Machining Centre Allowing for the Influence of Interchangeable Spindle Heads, Journal of Machine Engineering, 15/3, 19-32.

[9] WEGENER K., MAYR J., MERKLEIN M., BEHRENS B.A., AOYAMA T., SULITKA M., FLEISCHER J., GROCHE P., KAFTANOGLU B., JOCHUM N., MÖHRING H.C., 2017, Fluid elements in machine tools, CIRP Annals, 66/2, 611-634.

[10] SHABI L., WEBER J., WEBER J., 2017, Model-based Analysis of Decentralized Fluidic Systems in Machine Tools, in: Proceedings of $15^{\text {th }}$ Scandinavian International Conference on Fluid Power, Enhancing safety of independent metering systems for mobile machines, Linköping University Electronic Press, Linköping, Sweden, 116-123.

[11] UHLMANN E., SALEIN S., 2016, Konzepte zur energieautarken Kühlung von Lineardirektantrieben, Zeitschrift für wirtschaftlichen Fabrikbetrieb, 111/7-8, 411-415.

[12] UHLMANN E., SALEIN S., 2017, Energieautarke Kühlung von Lineardirektantrieben, wt Werkstattstechnik Online, 107/5, 359-365.

[13] JUNIOR C., 2010, Analyse thermoelektrischer Module und Gesamtsysteme, Diss, Braunschweig, Germany.

[14] MARTÍNEZ A., ASTRAIN D., RODRÍGUEZ A., 2013, Dynamic model for simulation of thermoelectric selfcooling applications, Energy, 55, 1114-1126.

[15] MARTÍNEZ A., ASTRAIN D., RODRÍGUEZ A., 2011, Experimental and analytical study on thermoelectric selfcooling of devices, Energy, 36/8, 5250-5260.

[16] KIFLEMARIAM R., LIN C.X., 2015, Numerical simulation of integrated liquid cooling and thermoelectric generation for self-cooling of electronic devices, International Journal of Thermal Sciences, 94, 193-203.

[17] UHLMANN E., PRASOL L., THOM S., SALEIN S., WIESE R., 2018, Development of a dynamic model for simulation of a thermoelectric self-cooling system for linear direct drives in machine tools, Conference on Thermal Issues in Machine Tools, Proceedings, CIRP Sponsored Conference, Dresden, Verlag Wissenschaftliche Scripten, Auerbach/Vogtland, Germany, 75-91.

[18] HOLMAN J.P., 2010, Heat transfer, McGraw-Hill Higher Education, Boston, Mass. 